\title{
PERAN PEMERINTAH DALAM PEMULIHAN EKONOMI UMKM DALAM SEKTOR TEKNOLOGI (PADI UMKM)
}

\author{
DJIHADUL MUBAROK1, DARU SUSANTI2 \\ djihadulmubarok@ibm.ac.id1, darususanti@ibm.ac.id2
}

\author{
Program Studi Ekonomi Pembangunan Institut Bisnis Muhammadiyah Bekasi
}

\begin{abstract}
ABSTRAK
Masalah yang diangkat dalam penelitian ini adalah bagaimana peran pemerintah dalam pemulihan ekonomi UMKM di Indonesia di masa pandemik Covid-19 di dalam sektor teknologi (PaDi UMKM) serta konsep yang digunakan platform tersebut dengan metode penelitian digunakan adalah penelitian kualitatif yang bersifat kepustakaan (library research), penelitian ini diperoleh dengan melakukan pengkajian yang bersumber dari penelitian, buku, berita dan data statistik tentang informasi PaDi UMKM.
\end{abstract}

Kata Kunci :UMKM, PaDi UMKM, Flatform digital UMKM

\section{ABSTRACT}

The problem raised in this research is how the role of the government in the economic recovery of UMKM in Indonesia during the Covid-19 pandemic in the technology sector (PaDi UMKM) and the concept used on the platform with the research method used is qualitative research which is library research, this research is obtained by conducting studies that come from research, books, news and statistical data about information on PaDi UMKM.

Keywords: UMKM, PaDi UMKM, Digital Platform

\section{PENDAHULUAN}

\section{Latar Belakang Masalah}

Dampak dari Covid-19 yang terjadi dari tahun 2020 hingga tahun 2021 bukan hanya terjadi pada masalah kesehatan yang melanda di Indonesia, banyak efek dari wabah ini yang juga terdampak bukan hanya di kesehatan tetapi salah satunya dalam bidang perekonomian di Indonesia yang menurun drastis apa lagi dari faktor penurunan usaha. Berdasarkan sumber dari Badan Pusat Statistik (BPS) ${ }^{1}$ tahun 2018, jumlah Usaha Mikro Kecil Menengah (UMKM) terdata 64.2 juta unit menutup usahanya dan survei dari ADB (Asian Development Bank menyatakan hamper 50 persen UMKM menutup usahanya. Penurunan penjualan atau penghasilan UMKM terdata dalam survei

1Badan Pusat Statistik. diakses 4 Mei 2021. 
http://lipi.go.id ${ }^{2}$ pada tahun 2020 melibatkan 679 responden sebagai pelaku UMKM menunjukan penurunan selama pandemi sekitar $94.69 \%$.

https://kemenkopukm.go.id ${ }^{3}$ disebutkan pada tahun 2020 terdata 55.2 juta unit UMKM mampu menyerap sekitar 101.7 juta orang tenaga kerja. UMKM juga sebagai sarana untuk meningkatkan perekonomian rakyat serta memberikan masukan devisa bagi negara.

Dari jumlah unit UMKM tersebut sangat sedikit memanfaatkan teknologi untuk mengembangkan usahanya yang sangat berdampak pada penghasilan usaha, berdasarkan riset pro.ristek brin ${ }^{4}$ dalam transaksi digital baru 1,5 juta UMKM di Indonesia yang sudah menggunakan proses online ini. Padahal menurut Agustina Erni sebagai Deputi Bidang Kesetaraan Gender terdapat 10.2 juta UMKM berpotensi untuk menggunakan bisnis online ini.

Berdasarkan data tersebut, perlunya peranan pemerintah untuk meningkatkan daya tahan pelaku UMKM dalam menopang perekonomian UMKM di masa pandemi Covid-19 ini.

\section{Rumusan Masalah}

Masalah yang diangkat dalam penelitian ini adalah bagaimana peran pemerintah dalam pemulihan ekonomi UMKM di Indonesia di masa pandemik Covid-19 di dalam sektor teknologi

\section{Tujuan Penelitian}

Penelitian yang ingin dicapai dalam penelitian ini adalah:

1. Mengetahui peran pemerintah dalam pemulihan ekonomi UMKM di Indonesia di masa pandemik Covid-19 di dalam sektor teknologi PaDi UMKM)

\footnotetext{
2 http://lipi.go.id/berita/survei-kinerja-umkm-dimasa-pandemi-covid19/22071. Diakses 4 Mei 2021 3 https://kemenkopukm.go.id/read/teten-targetlima-tahun-ke-depan-sebanyak-48-000-usahakecil-naik-kelas. Diakses 4 Mei 2021
}

Pemerintah meyakini bahwa UMKM salah satu faktor penggerak perekonomian Indonesia, karena dalam hal ini penyerapan tenaga kerja oleh UMKM sangat tinggi hal ini terbukti pada

2. Mengetahui bagaimana konsep interaksi yang terdapat di PaDi UMKM

\section{Manfat Penelitian}

Manfaat hasil dari penelitian ini diharapkan dapat menjadi pengetahuan tentang informasi usaha pemerintah Indonesia dalam memperbaiki perekonomian UMKM dalam sisi teknologi.

\section{TINJAUAN PUSTAKA}

Alvin Edgar Permana, Arvy Muhammad Reyhan, Hidayatul Rafli. Nur Aini Rakhmawati (2021) dalam penelitiannya Analisis Transaksi Belanja Online Pada Masa Pandemi Covid-19. Berdasarkan hasil penelitiannya bahwa penggunaan Pada masa pandemic E-Commerce oleh masyarakat dalam memenuhi kebutuhan sehari-hari.

Mansyur. (2015) Business to Business (B2B) E-Marketplace Sebagai Media Promosi, distudinya meneliti tentang merancang sistem informasi sebagai media promosi secara online bagi UKM dengan menggunakan model business to business (B2B) serta E-market untuk memberikan peluang kepada pelaku UKM untuk mempromosikan juga mengembangkan produknya agar menjadi suatu kemandirian dalam masyarakat untuk menghadapi masyarakat ekonomi ASEAN (MEA) . Mansyur menjelaskan bahwa terdapat tiga e-Marketplace yaitu e-Marketplace privat berhubungan secara individu-individu, eMarketing Public adalah berhubungan

4

https://risetpro.ristekbrin.go.id/web/2020/10/15/pe manfaatan-teknologi-untuk-umkm-belum-merata/. Diakses 4 Mei 2021 
dengan barang dan jasa yang dilaksanakan oleh pemerintah/instansi yang bersifat umum. Selain itu e-Marketplace Konsorsium adalah gabungan dari beberapa perusahaan yang bekerjasama dalam suatu proyek. Aplikasi eMarketplace mempunyai beberapa fasilitas untuk kemudahan informasi produk yang ditawarkan (offer to buy), dicari (offer to sell) dan produk lelang.

Wan Lauran Hardilawati (2019) Strategi Bertahan di Tengah Pandemi Covid 19. bahwa dalam hasil penelitian ini menyarankan strategi bertahan untuk UMKM untuk dapat melakukan perdagangan secara e-commerce, serta melakukan pemasaran secara digital, perbaikan kualitas produk dan peningkatan pelayanan sekaligus menjalin dan memaksimalkan hubungan dengan konsumen.

Ade dan Yoyok Cahyono.(2021). Strategi Pemulihan Pemasaran UMKM di Masa Pandemi Covid 19 Pada Sektor Ekonomi Kreatif. Menyimpulkan dalam studinya adalah penyusunan pemasaran dalam berwirausaha pada sektor ekonomi kreatif dapat direncanakan melalui STP (Segmenting, Targeting dan Positioning) dalam menarik konsumen. Dalam faktor pendukung dari suatu usaha di masa pandemic Covid 19 agar berjalan efektif serta efisien adalah menerapkan konsep promotion, service excellent customers rewards, afiliasi atau kemitraan dan modal sosial,
Berdasarkan kesimpulan tinjauan pustaka oleh peneliti bahwa penting suatu strategi untuk pemulihan serta peningkatan ekonomi pada bidang UMKM pada masa pandemic Covid 19, melakukan pemasaran melalui digital serta menerapkan kemitraan, maka dari itu pentingnya peran pemerintah dalam pemulihan ekonomi UMKM dalam sektor Teknologi

\section{METODE PENELITIAN}

\section{Metode penelitian}

Penelitian yang dilakukan menggunakan metode kualitatif yang bersifat kepustakaan (library research), penelitian ini diperoleh dengan melakukan pengkajian yang bersumber dari penelitian, berita online dan data statistik

\section{HASIL PEMBAHASAN}

\section{Penggunaan Marketplace di Indonesia}

Berdasarkan penelitian dari jurnal Analisa Transaksi Belanja Online Pada Masa Pandemi Covid-19 (Alvin Edgar Permana: 2021) menyimpulkan bahwa pandemik di Indonesia sangat berpengaruh terhadap penggunaan E-Commerce oleh masyarakat hingga meningkat sebanyak $38 \%$ hingga saat ini. Hal ini didukung juga akan survei penggunaan marketplace yang digunakan oleh masyarakat Indonesia, hal ini terdapat dalam tabel di bawah ini: 


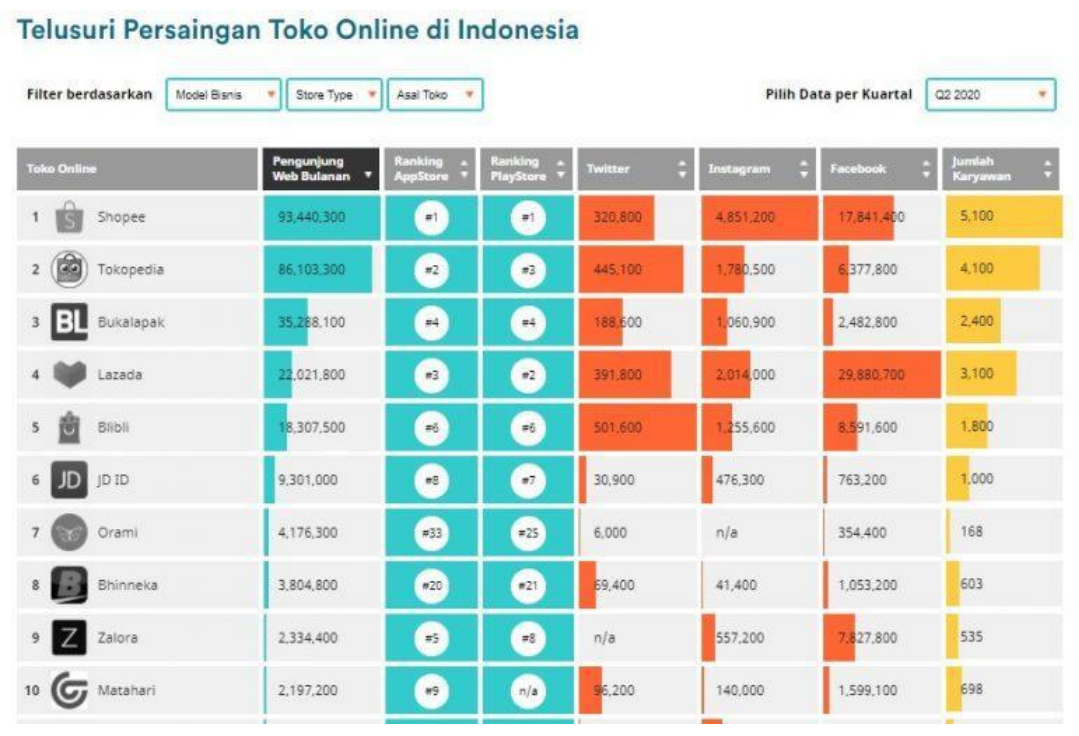

Tabel 1: 10 Terbesar Penggunaan Marketplace di Indonesia (website e-commerce terbaik)

\section{Pendirian Platform Pasar Digital (PaDi) UMKM}

Seiring dengan perkembangan teknologi di era digital ini, UMKM harus ikut serta mengikuti pola perkembangan usaha agar tidak tertinggal jauh dan berdampak mengurangi pendapatan usaha. Menurut Kurniawan dan Asharudin pola pemasaran dalam usaha berubah sangat cepat, keberadaan teknologi yang semakin berkembang dimana salah satunya pelanggan dapat melakukan transaksi dengan beberapa aplikasi yang telah terbentuk.

PaDi UMKM adalah sebuah platform marketplace yang dibentuk oleh Kementerian BUMN pada 17 Agustus 2020, yang merupakan kerjasama Kementerian BUMN, Kementerian Koperasi dan UKM dan juga Lembaga Kebijakan Perdagangan Barang Jasa Pemerintah. Tujuan dari marketplace ini agar UKM dengan mudah membuka akses pasar untuk masuk dalam pengadaan barang dan jasa pemerintah khususnya BUMN. Menurut Kementerian BUMN bahwa program ini sudah tembus Rp. 11.4 triliun per Januari 2021, Menteri BUMN
Erick Thohir telah menyiapkan dana sejumlah Rp. 18.52 triliun untuk platform PaDi dan menurut wakil menteri BUMN Kartika Wirjoatmodjo mengatakan data 14 miliar merupakan operasional expenditure/opex dan capital expenditure/capex.

\section{Tujuan Berdirinya Pasar Digital (PaDi) UMKM}

Pasar Digital (PaDi) UMKM adalah platform yang dibentuk oleh Kementerian BUMN bersama BUMN untuk mengetahui perkembangan UMKM di Indonesia yang juga menjadi pusat data (Control Tower Dashboard) UMKM. Konsep ini untuk mengumpulkan data yang akurat mengenai usaha mikro, kecil dan menengah secara lengkap dan juga untuk dasar analisis penentu kebijakan.

Konsep digital ini untuk memperkuat penjualan UMKM sebagai penggerak ekonomi Indonesia sebagai usaha menghadapi persaingan global. Dalam kata lain pemerintah ingin meningkatkan kapasitas UMKM, dan BUMN juga memberikan ruang kepada pelaku UMKM 
untuk menjadi vendor atau supplier kepada BUMN.

\section{PaDi UMKM Hasil Kolaborasi 9 BUMN}

Teknologi di era digital ini sangat mendukung pertumbuhan di sektor perekonomian terutama UMKM, menurut kemajuan teknologi adalah salah satu faktor pendukung dalam pertumbuhan ekonomi Kemajuan teknologi merupakan salah satu faktor dalam pertumbuhan ekonomi. Secara matematis hubungan antara kemajuan teknologi dengan pertumbuhan ekonomi telah dikemukakan oleh para ekonom seperti Abramovitz, Kendrick dan Solow. Gabungan kolaborasi bersama Sembilan BUMN untuk membentuk platform digital sebagai wadah pengembangan potensi pelaku ekonom lokal di Indonesia yang dinamakan Pasar Digital UMKM atau yang dikenal PaDi UMKM, berikut ini adalah kolaborasi PaDi UMKM:

1. Kementerian BUMN sebagai inisiator ekosistem PaDi UMKM bersama UMKM dalam membangun tulang punggung perekonomian Indonesia.

2. BUMN sebagai pasar produk lokal; UMKM dan merekomendasikan
UMKM binaan untuk bergabung dalam PaDi UMKM.

3. BUMN financing sebagai fund owner yang menyediakan modal usaha dan produksi bagi UMKM.

4. Telkom Group sebagai penyedia platform digital dan orkestrasi ekosistem.

\section{Jenis Interaksi Marketplace Pasar Digital (PaDi) UMKM}

B2B (Business to Business) Transaksi UMKM dan BUMN

Pengertian B2B pada penelitian oleh Mansur adalah sebuah pasar yang disediakan oleh online, dimana tempat mempromosikan dan pertukaran barang atau jasa secara elektronik sehingga dapat mengurangi sekecil mungkin kelemahan pada sistem transaksi manual. Demikian juga pada system yang diterapkan PaDi UMKM ini adalah transaksi bisnis antar pelaku bisnis dengan pebisnis lainnya, dapat berupa kesepakatan spesifik yang mendukung kelancaran pebisnis. sehingga peran PaDi UMKM B2B sebagai Pasar Digital bagi BUMN untuk melakukan transaksi pembelanjaan ke UMKM dengan sistem B2B.

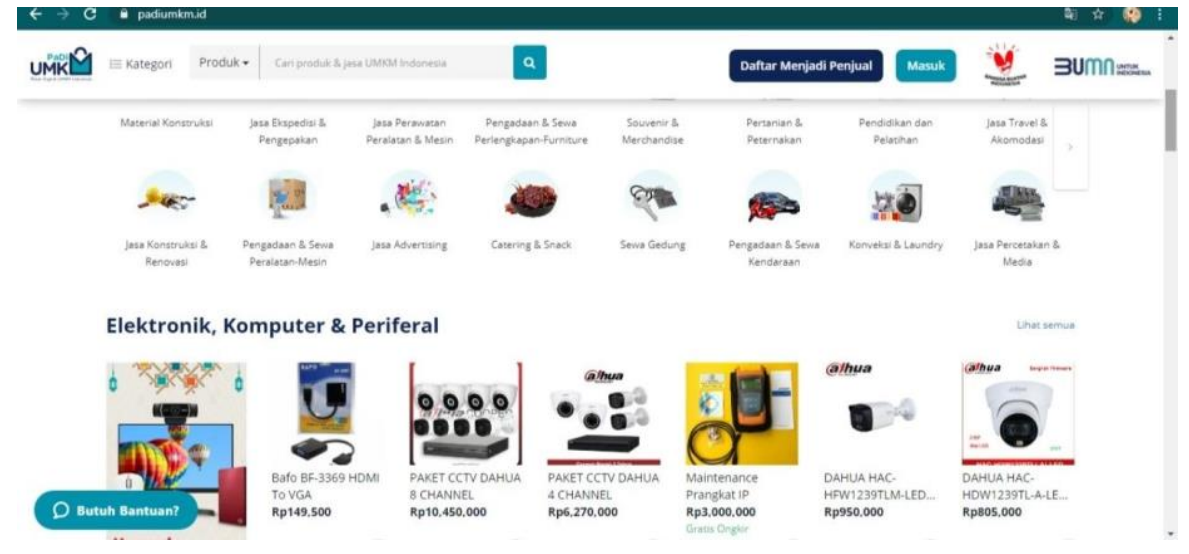

Gambar 1: Fiture B2B (Mansyur)

\section{B2C (Business to Customer)}

Melakukan aktivitas yang dilakukan produsen kepada konsumen secara langsung, platform PaDi UMKM juga membantu UMKM untuk menghubungkan pasar B2C melalui marketplace. 


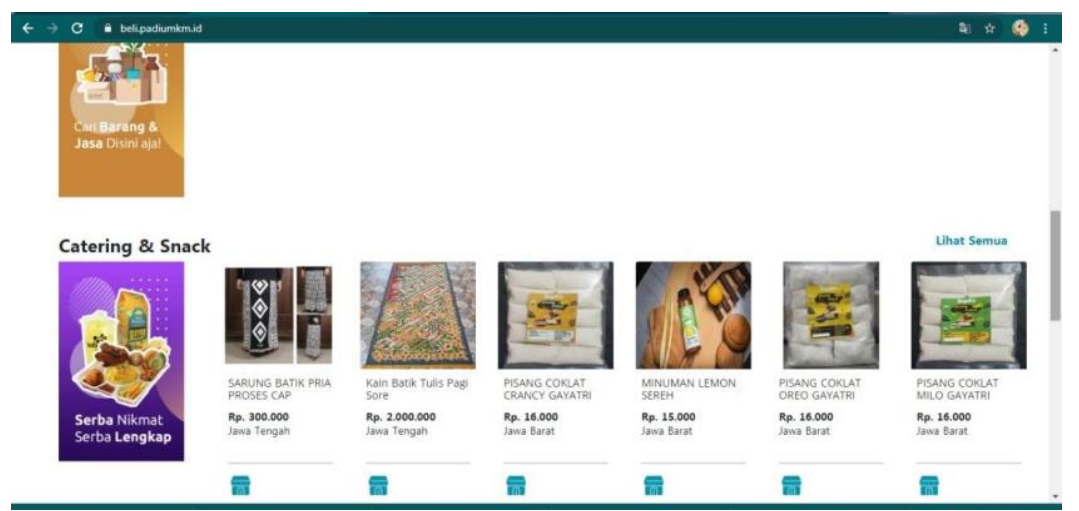

Gambar 2: Fiture Bisnis to Customer (B2C)

\section{PaDi UMKM Financing}

Membantu meningkatkan atau pengembangan dalam permodalan bisnis UMKM dalam fasilitas pembiayaan. Menteri BUMN Menteri BUMN Erick Thohir menyatakan PaDi UMKM merupakan teknologi yang programkan oleh BUMN kepada UMKM, yang hampir keseluruhan melibatkan pihak BUMN. Dalam suatu proses transaksi menggunakan pembayaran virtual account yang bekerja sama dengan Bank Himbara, pada rencana kedepan juga Bank Mandiri, BNI, BTN juga akan memperkokoh dalam kerjasama pembiayaan UMKM melalui PaDi UMKM. Pada saat ini kerjasama masih menggunakan bank BRI, Pegadaian dan PNM.

\section{Keunggulan Pengguna PaDi UMKM}

Platform ini terdiri dari beberapa pengguna yaitu, pemerintah, UMKM, BUMN, Bank/financing dan logistik. Beberapa keunggulan dari platform ini bagi pengguna adalah:

\begin{tabular}{|c|c|c|}
\hline NO & PENGGUNA & KEUNGGULAN PaDi UMKM \\
\hline 1 & UMKM & $\begin{array}{l}\text { 1. Akses lokal dan global e-commerce } \\
\text { 2. Kemudahan dalam proses pembiayaan } \\
\text { 3. Kepastian proses pembayaran } \\
\text { 4. Pasar yang pasti di perusahaan BUMN } \\
\text { 5. Feedback dan penilaian produk }\end{array}$ \\
\hline 2 & Pemerintah & $\begin{array}{l}\text { 1. Data UMKM yang terverifikasi } \\
\text { 2. Profil lengkap UMKM Indonesia } \\
\text { 3. Data belanja BUMN }\end{array}$ \\
\hline 3 & $\begin{array}{l}\text { BUMN dan } \\
\text { Industri }\end{array}$ & $\begin{array}{l}\text { 1. Supplier produk lokal yang berkualitas dan terverifikasi } \\
\text { 2. Kepastian harga dan kualitas. }\end{array}$ \\
\hline 4 & Financing & Penyaluran pembiayaan yang terencana \\
\hline 5 & Logistik & $\begin{array}{l}\text { 1. Utilisasi aset dan transportasi logistic } \\
\text { 2. Memperluas last mile sampai ke lokasi UMKM }\end{array}$ \\
\hline
\end{tabular}

Tabel 1 Keunggulan Platform PaDi UMKM 
Di bawah ini adalah data yang bersumber dari bisnisukm.com (2021) https://bisnisukm.commengenai variasi produk yang bisa bergabung dalam PaDi UMKM:

1. Material Konstruksi

2. Jasa Konstruksi dan Renovasi

3. Pengadaan dan sewa peralatan mesin

4. Jasa ekspedisi dan pengepakan

5. Jasa perawatan peralatan dan mesin

6. Jasa advertising

7. Pengadaan dan sewa perlengkapan

8. Catering dan snack

9. Souvenir dan merchandise

10. Sewa gedung

11. Pertanian dan peternakan

12. Pengadaan dan sewa kendaraan

13. Pendidikan dan pelatihan

14. Konveksi dan laundry

15. Jasa travel dan akomodasi

16. Bagian jasa percetakan dan media

17. Perawatan kendaraan

18. Perawatan gedung

19. Jasa perawatan elektronik dan TI

20. Mandor dan tenaga kerja lain

21. Jasa event organizer

22. Alat dan jasa kesehatan dan keselamatan

23. Bahan kimia

24. Bahan elektronik komputer dan peripheral

25. Jasa konsultasi dan penilaian

\section{KESIMPULAN DAN SARAN}

\section{Peran Pemerintah dalam Pemulihan} Ekonomi UMKM di Sektor Teknologi.

Peran pemerintah dalam pemulihan ekonomi UMKM di Indonesia di masa pandemik Covid-19 di dalam sektor teknologi adalah salahnya satunya pendirian Platform Pasar Digital (PaDi) UMKM yang dibentuk oleh Badan Usaha Milik Negara (BUMN) yang bertujuan untuk untuk mengetahui perkembangan UMKM di Indonesia, menjembatani kerjasama antar usaha atau vendor, menjembatani penjual dan pembeli serta mempermudah peminjaman modal oleh bank dan konsep digital ini untuk memperkuat penjualan UMKM sebagai penggerak ekonomi Indonesia sebagai usaha menghadapi persaingan global serta pemulihan ekonomi dari pandemic Covid19.

\section{Konsep Interaksi di PaDi UMKM}

Terdapat dua jenis interaksi di platform PaDi UMKM adalah yang pertama B2B Business to Business yang menjembatani pelaku bisnis dengan pelaku bisnis lainnya. Kedua adalah B2C Business to Customer dimana pelaku usaha dapat berinteraksi langsung jual beli dengan konsumen. Platform ini juga membantu meningkatkan atau pengembangan dalam permodalan bisnis UMKM dalam fasilitas pembiayaan dengan bekerja sama dengan beberapa BANK dan Pegadaian.

Peran pemerintah sangat penting demi kemajuan dan pemulihan perekonomian UMKM di Indonesia, bukan hanya fasilitas yang sebagai perantara usaha tapi juga didukung dengan kemudahan perngurusan perizinan usaha agar UMKM menjadi suatu usaha yang mendukung perbaikan perekonomian Indonesia. 


\section{DAFTAR PUSTAKA}

Alvin Edgar Permana, Arvy Muhammad Reyhan, Hidayatul Rafli. Nur Aini Rakhmawati., $2021 \quad$ Analisis Transaksi Belanja Online Pada Masa Pandemi Covid-19. Sistem Informasi. Institut Teknologi Sepuluh Nopember. Surabaya.

Ade dan Yoyok Cahyono.

(2021). Strategi

Pemulihan Pemasaran UMKM di Masa Pandemi Covid 19 Pada Sektor Ekonomi Kreatif. Jurnal Teknologi dan Informasi Bisnis

Wan Lauran Hardilawati. 2019. Strategi Bertahan di Tengah Pandemi Covid 19. Universitas Muhammadiyah Riau, Fakultas Ekonomi dan Bisnis.

Face Digital Marketing. Muhammadiyah International Journal Economics and Business Volume, number 2 , December 2018. http://lipi.go.id/berita/survei-kinerjaumkm-di-masa-pandemi-covid19/22071

Mansyur. Business to Business (B2B) EMarketplace Sebagai Media Promosi
Kurniawan, A \& Azharuddin, M. 2018. Small And Medium Enterprises (SMEs)

Produk Usaha Kecil Menengah (UKM). Politeknik Negeri Bengkalis

https://kemenkopukm.go.id/read/tetentarget-lima-tahun-ke-depan sebanyak-48000-usaha-kecil-naik-kelas

https://risetpro.ristekbrin.go.id/web/2020/1 0/15/pemanfaatan-teknologi-untuk-umkmbelum-merata/

https://qwords.com/blog/websiteecommerce-terbaik/

https://tirto.id/kemenbumn-transaksipasar-digital-sudah-tembus-rp114-triliungaij

https://www.inews.id/finance/makro/doron g-umkm-jadi-vendor-proyek-bumnplatform-padi-dirilis-agustus-2020

https://info.padiumkm.id/about/diakses 5 Mei 2021

https://bisnisukm.com/padi-umkmindonesia-marketplace-baru-untuk-produkusahamu.html 